\title{
A Educação do Campo na pesquisa em Ensino de Ciências e Matemática: um levantamento
}

C

\author{
The Countryside Education in the Sciences and Mathematics \\ teaching research: a survey
}

\section{La Educación Rural en la investigación en la Enseñanza de las Ciencias y las Matemáticas; una encuesta}

Andressa Franco Vargas ${ }^{1}$; Gabriel de Oliveira Soares ${ }^{1}$; Eleni Bisognin ${ }^{1}$

\section{RESUMO}

O presente trabalho visa analisar e mapear as produções de programas de pós-graduação referentes ao ensino de Ciências e Matemática voltadas para a modalidade da Educação do Campo. Para alcançar tal objetivo realizamos uma pesquisa em plataformas digitais sobre os temas citados, em busca de produções que discutissem o Ensino de Ciências e Matemática para uma análise em momento posterior. Durante as análises observamos a diversidade de produções, uma vez que foram encontrados trabalhos que abrangem diversos ramos da Ciência e da Matemática. Após as análises foi possível identificar que apesar de muitas propostas prezarem pelo Ensino de Ciências e Matemática ainda há uma compartimentalização de saberes. Ainda, fica evidente que todas as propostas e discussões que envolvem as temáticas de Currículo e Formação de Professores propõem formação continuada e adequações pedagógicas e organizacionais para que as escolas do campo atendam as necessidades da comunidade. Frente a isto, as publicações voltadas para o Ensino e Aprendizagem, prezam por garantir que os aspectos da comunidade e da vida no campo sejam enaltecidos nas práticas escolares, uma vez que se preocupam com a questão de dar significados aos conhecimentos escolares por meio da cultura. Para concluir, ressaltamos o quão é importante a construção e implementação de propostas que diferenciem o currículo das escolas do campo, uma vez que estas vão ao encontro dos documentos oficiais que regem a Educação do Campo no Brasil, prezando pela cultura, crenças e saberes oriundos de aspectos socioculturais e são uma alternativa para a descompartimentalização dos saberes.

Palavras-chave: Educação do Campo; Ensino de Ciências e Matemática; Formação de Professores; Currículo.

\begin{abstract}
The present work aims at analyzing and mapping the productions of post-graduation programs referring to the teaching of Science and Mathematics designed for the Field Education. In order to reach such objective, we realized a research in digital platforms concerning the foresaid themes, looking for productions which discussed the Teaching of Science and Mathematics for a posterior evaluation. During the analysis, we observed the diversity of productions, as the works found approached several fields of Science and Math. After all analysis, it was possible to identify that apart many proposals render to the Teaching of Science and Math, there is still a knowledge
\end{abstract}

${ }^{1}$ UFN - Universidade Franciscana, Santa Maria/RS - Brasil. 
compartmentalization. In addition, it is evident that all proposals and discussions that involve the Curriculum and Teachers Formation subjects propose continuous education and pedagogical and organizational adequacies so that field schools can answer the community needs. Considering this, the publications about Teaching and Learning render for guaranteeing that the community aspects and the countryside lifestyle are praised in the school practices, as they are concern the idea of giving meaning and scholar knowledge by means of culture. To sum up, we highlight how important it is to build and implement the proposals which differentiate the curriculum of field schools, because they are in accordance to the official documents that rule the Field Education in Brazil, valuing culture, beliefs and knowledge coming from the sociocultural aspects and are an alternative for the knowledge decompartmentalization.

Keywords: Countryside Education; Sciences and Mathematics Teaching; Teachers Formation; Curriculum.

\section{RESUMEN}

El presente trabajo tiene como objetivo analizar y mapear la producción de programas de posgrado relacionados con la enseñanza de Ciencias y Matemáticas centrados en el campo de la Educación Rural. Para lograr este objetivo, realizamos una investigación en plataformas digitales sobre los temas mencionados, en busca de producciones que discutieran la Enseñanza de la Ciencia y las Matemáticas para su análisis en un momento posterior. Durante los análisis observamos la diversidad de producciones, ya que se encontraron trabajos que cubren diferentes ramas de la Ciencia y las Matemáticas. Después del análisis, fue posible identificar que a pesar de muchas propuestas que valoran la Educación en Ciencias y Matemáticas, todavía existe una compartimentación del conocimiento. Aún así, es evidente que todas las propuestas y discusiones que involucran los temas de Currículo y Capacitación de Maestros proponen capacitación continua y ajustes pedagógicos y organizativos para que las escuelas rurales satisfagan las necesidades de la comunidad. En vista de esto, las publicaciones centradas en la Enseñanza y el Aprendizaje se preocupan por garantizar que los aspectos de la comunidad y la vida en el campo se destaquen en las prácticas escolares, ya que están preocupados por el tema de dar significado al conocimiento escolar a través de la cultura. Para concluir, enfatizamos lo importante que es construir e implementar propuestas que diferencien el currículo de las escuelas rurales, ya que cumplen con los documentos oficiales que rigen la Educación Rural en Brasil, valorando la cultura, creencias y conocimientos derivados de aspectos socioculturales y son una alternativa para la descompartimentalización del conocimiento.

Palabras-clave: Educación rural; Enseñanza de ciencias y matemáticas; Formación docente; Currículo.

\section{INTRODUÇÃO}

Uma das maiores preocupações da atualidade em se tratando da educação é a qualidade do ensino e da aprendizagem dos alunos nas escolas brasileiras, o que abre a discussão para tópicos como: Quais as alternativas possíveis parar melhorar o cenário atual? Quais fatores influenciam no ensino? Quais alternativas utilizar para o desenvolvimento da aprendizagem? Como estimular o interesse dos alunos durante as aulas? Entre outros.

Porém, os desafios se tornam ainda maiores quando começamos a discutir a educação nos moldes das escolas do campo pois, além da preocupação com a aprendizagem e rendimento dos alunos, os educadores e as instituições devem discutir questões como currículo, flexibilidade e formação continuada de professores, por se tratar de uma realidade totalmente distinta do modelo educacional instaurado em escolas de regiões urbanas. 
Deste modo, neste trabalho, traçamos como objetivo mapear e analisar as produções acadêmicas em programas de pós-graduação no âmbito do ensino de Ciências e Matemática voltado à modalidade da Educação do Campo, com o intuito de explorar as principais alternativas que estão sendo desenvolvidas para suprir as necessidades destas comunidades.

Para alcançar tal objetivo, realizamos uma busca em plataformas digitais a procura de trabalhos que contemplassem a ideia de ensino e aprendizagem voltados para a educação do campo, refinando os resultados para o ensino de Ciências e Matemática.

Assim, após a análise, apontamos algumas considerações referentes às perspectivas encontradas nos trabalhos, os modelos de aprendizagem e o que podemos esperar de avanços com relação à Educação do Campo.

\section{O ENSINO DE CIÊNCIAS E MATEMÁTICA NO BRASIL}

O Ensino de Ciências e Matemática hoje é uma das principais bases para o desenvolvimento da ciência e da tecnologia na sociedade, sendo estes elementos que constituem as diversas manifestações culturais e sociais (ABRAPEC, 2011).

Deste modo, quando discutimos o ensino, devemos levar em consideração aspectos como a natureza da abordagem e das ações, como por exemplo, com que tipo de comunidade se está trabalhando e o que desejamos construir, compreender e valorizar e, como consequência, onde se desejamos chegar com estas práticas.

Comumente, costumamos valorizar apenas resultados finais de nossas atividades e práticas oriundas do contexto educacional e acabamos por esquecer que os momentos mais ricos consistem nos caminhos para se chegar ao fim, ou seja, as etapas, os métodos, as explorações e a colaboração dos alunos, com o intuito de incentivar a formação de futuros pesquisadores e cientistas, além de promover alternativas para um ensino de qualidade.

Porém, nossa realidade com relação ao Ensino de Ciências e Matemática ainda é diferente. Segundo a Associação Brasileira de Pesquisa em Ciências (ABRAPEC) (2011) a má formação da população brasileira nestas áreas pode ser evidenciada em muitos programas de avaliação da aprendizagem como o Índice de Desenvolvimento da Educação Básica (IDEB), Exame Nacional de Desemprenho dos Estudantes (ENADE), Exame Nacional do Ensino Médio (ENEM) e outros.

Assim, começa-se a busca por fatores que constroem nosso cenário atual, ressaltando que algumas das possíveis causas podem ser: a) a falta de incentivo familiar; b) a falta de significação quanto aos conceitos, c) a forma de abordagem e d) a desvalorização do professor (PACHECO, ANDREIS, 2017).

Diante disso, citamos Lorenzato (2010) quando ressalta que estes fracassos escolares, estão ligados principalmente aos primeiros anos, não sendo culpa dos professores dos anos iniciais mas sim, de questões sociais sobre a formação científica e matemática.

Mesmo com esta situação, acreditamos ser válido destacar o percurso já caminhado pela comunidade, este constituído de pesquisas, alternativas, projetos e propostas que envolvem professores e escolas desde a década de 50 em nosso país, propondo ações para a expansão e qualificação da pós-graduação, 
oportunizando alternativas e momentos para a contribuição de conceitos em conjunto com a transformação social (ABRAPEC, 2011).

Deste modo, estratégias estão sendo implementadas para a elaboração do plano nacional de Ciência e Tecnologia, contemplando a formação inicial e continuada de professores, o fortalecimento da pósgraduação, o fomento de eventos, projetos e parcerias, bem como, a criação de condições estruturais e curriculares nas escolas, além da criação de incisos em políticas públicas para assegurar aos alunos e professores direitos mais plausíveis, fortalecendo o ensino científico e matemático (ABRAPEC, 2011, p. 7).

Por fim, ressaltamos o papel do professor nesse processo, não consistindo em uma tarefa fácil, esta adaptação a novos horizontes educacionais. Entretanto, por vezes se faz necessário, uma vez que devemos acompanhar a evolução de nossos alunos e tentar levar a ciência de modo geral ao encontro destas evoluções, considerando que o saber científico move o mundo e assim, não podemos deixar que nossas gerações de alunos estacionem no tempo.

\section{A EDUCAÇÃO DO CAMPO}

A Educação do Campo é uma modalidade de ensino ofertada em comunidades de difícil acesso, como regiões indígenas, quilombolas, assentamentos e ribeirinhos, com o intuito da promoção do fortalecimento, a oferta e a ampliação da educação básica e do ensino superior, conforme o decreto $\mathrm{n}^{\circ}$ 7.352, de 4 de novembro de 2010.

Devido à pluralidade cultural presentes nestas regiões onde estão situadas escolas do campo, as práticas educacionais devem prezar pela valorização de cada cultura, de modo a reconhecer a importância da mesma para a comunidade e, para adequação de suas práticas pedagógicas.

Em termos de estado, o Rio Grande do Sul, conta com aproximadamente 2.268 escolas do campo em funcionamento, espalhadas por diversas regiões, abrangendo um público diversificado, o que acarreta na ampliação do campo de conhecimentos que podem ser explorados, sendo estes, oriundos de práticas como pecuária, agricultura, pesca e indústrias têxtis. Porém, adentramos em outra questão cercada de discussão: a diferenciação proposta pelo próprio governo com relação à qualidade do ensino em localidades rurais e urbanas.

Corroboramos com Silva (2017) sobre a diferenciação deste ensino sobre questões como infraestrutura e formação docente, pois muito se cobra sobre ensino de qualidade e adaptações para a Educação do Campo, porém pouco é o investimento nestas comunidades.

Ainda, ressaltamos a ideia de Leite (2002), quando destaca que esta modalidade de ensino sempre foi deixada de lado pela União, dispondo sempre de recursos e atenção inferiores a escolas da zona urbana, ou seja, a educação podia ser vista como um privilégio para pessoas do campo e da roça.

Assim, no decorrer dos anos, alguns movimentos sociais como o Movimento Sem Terra (MST) buscaram, por meio de reivindicações alguns direitos para as escolas do campo no Brasil. São eles: alimentação, 
transporte, recursos financeiros, materiais pedagógicos e, principalmente, uma adaptação curricular mais do que necessária, levando em conta a pluralidade cultural e as características das comunidades.

Logo, ressaltamos a importância de preparar o professor para ingressar e desenvolver seu trabalho nestas comunidades pois, mesmo que a União esteja presa à ideia de um modelo educacional "urbanoide", sabe-se o quanto é importante dar sentido ao aprendizado, devendo partir de situações cotidianas, para que a partir disso, o aluno admita sentido tanto para os conhecimentos científicos tanto para os conhecimentos oriundos de sua própria vivência como o meio em que vive.

\section{PERCURSO METODOLÓGICO}

Com o intuito de mapear as produções relacionadas ao tema, optamos por realizar uma busca em duas plataformas digitais: a) Catálogo de Teses e Dissertações da CAPES; b) Biblioteca Digital de Teses e Dissertações. Assim, utilizamos como conetivos de busca os termos "Ensino" AND "Aprendizagem" AND "Educação do Campo". Assim, elencamos as produções encontradas referentes ao primeiro semestre de 2019.

Neste primeiro levantamento encontramos 213 trabalhos de diversas áreas do conhecimento, como Geografia, Educação Física, Ciências Ambientais, Sociologia, Educação Rural, entre outras. Para selecionar trabalhos que discutissem o Ensino de Ciências e Matemática, realizamos um refinamento selecionando apenas produções que contemplassem estas áreas de conhecimento.

Após esta filtragem, as produções foram analisados 21 trabalhos, nos quais se discutiam ideias referentes ao Ensino de Matemática, o Ensino de Ciências, a questão multidisciplinar e a Educação Científica e Tecnológica.

Para analisar as produções encontradas, decidimos estabelecer categorias após a leitura dos resumos e palavras-chave. São elas: Ensino de Matemática, Ensino de Ciências, Ensino de Física, Formação de Professores, Currículo e Pedagogia da Alternância. Assim, as análises serão apresentadas a partir de cada categoria, onde discutiremos alguns pontos chave de cada uma das produções.

\section{RESULTADOS}

\subsection{Publicações referentes ao Ensino de Matemática}

Para esta categoria foram elencados 4 trabalhos, no quais discutiam aspectos relacionados ao Ensino de Matemática e sua aplicabilidade na Educação do Campo. O Quadro 1, sintetiza as publicações desta categoria.

Quadro 1 - Publicações sobre o Ensino de Matemática.

\begin{tabular}{|c|c|c|c|c|}
\hline Autor & Título & Ano & Programa & Instituição \\
\hline $\begin{array}{c}\text { Simone } \\
\text { Rodrigues } \\
\text { Martins Santos }\end{array}$ & $\begin{array}{c}\text { Ensinar Matemática Na } \\
\text { Educação Infantil do campo: } \\
\text { análise em Escolas do } \\
\text { município De Igarassu }\end{array}$ & 2018 & $\begin{array}{c}\text { Programa de Pós- } \\
\text { Graduação Em } \\
\text { Educação Matemática } \\
\text { e Tecnológica }\end{array}$ & $\begin{array}{c}\text { Universidade } \\
\text { Federal do } \\
\text { Pernambuco }\end{array}$ \\
\hline
\end{tabular}




\begin{tabular}{|c|c|c|c|c|}
\hline $\begin{array}{c}\text { Debora de Sales } \\
\text { Fontoura da Silva } \\
\text { Frantz }\end{array}$ & $\begin{array}{c}\text { Potencialidades da Fotografia } \\
\text { para O Ensino de Geometria e } \\
\text { Proporção Em uma escola Do } \\
\text { Campo }\end{array}$ & 2015 & $\begin{array}{c}\text { Programa de Pós- } \\
\text { Graduação Em Ensino } \\
\text { de Matemática }\end{array}$ & $\begin{array}{c}\text { Universidade } \\
\text { Federal do Rio } \\
\text { Grande do Sul }\end{array}$ \\
\hline $\begin{array}{c}\text { Luciana Boemer } \\
\text { Cesar Pereira }\end{array}$ & $\begin{array}{c}\text { Ensino de Estatística Na } \\
\text { escola do Campo: uma } \\
\text { proposta para o 60 ano do } \\
\text { Ensino Fundamental }\end{array}$ & 2013 & $\begin{array}{c}\text { Graduação em Ensino } \\
\text { de Ciências e } \\
\text { Tecnologia }\end{array}$ & $\begin{array}{c}\text { Universidade } \\
\text { Tecnológica do } \\
\text { Pará }\end{array}$ \\
\hline $\begin{array}{c}\text { Samya de } \\
\text { Oliveira Lima }\end{array}$ & $\begin{array}{c}\text { Ensino de Matemática na } \\
\text { Educação do Campo: um } \\
\text { estudo de caso no Curso } \\
\text { Pronacampo - URCA }\end{array}$ & 2017 & $\begin{array}{c}\text { Graduação em Ensino } \\
\text { de Ciências e } \\
\text { Educação Matemática }\end{array}$ & $\begin{array}{c}\text { Universidade } \\
\text { Estadual da } \\
\text { Paraíba }\end{array}$ \\
\hline
\end{tabular}

Fonte: Dados da pesquisa.

A produção de Santos (2018) busca discutir como ensinar Matemática na Educação Infantil em escolas do campo, especificamente na rede municipal de ensino do município de Igarassu. Deste modo, a autora traça como seu objetivo geral, analisar o Ensino de Matemática na Educação Infantil do Campo da rede municipal de ensino de Igarassu, com o intuito de discutir questões como, quais são os conteúdos matemáticos e os recursos trabalhados pelos professores e, como os mesmos compreendem e vivenciam a Matemática da Educação Infantil da Escola do Campo.

Para alcançar tal objetivo, a autora baseou-se em questionários e observações das aulas e do ambiente escolar, sendo estes contemplados por diários de campo e entrevistas com duas professoras da instituição. Após análise dos dados obtidos, a autora constatou os seguintes fatos: a) Os professores da Educação do Campo de modo geral participam de formações coletivas, juntamente com professores da zona urbana, ou seja, não há um amparo especifico para esta realidade; b) As duas instituições são desprovidas de recursos e materiais e financeiros; c) A escola A, pouco explora as possíveis articulações entre a Educação do Campo e o Ensino de Matemática; d) A escola B conta com projetos a fim de valorizar o campo e as práticas docentes engajadas nestes saberes.

Logo, a autora conclui que somente a escola B se preocupa com as articulações entre o campo e o ensino de Matemática, uma vez que a equipe gestora se prega pelo desenvolvimento de projetos na escola e com a dinâmica dos conteúdos e a prática da sala de aula.

A próxima produção analisada foi a de Frantz (2015) em que a mesma buscou explorar na fotografia, potencialidades para o Ensino de Geometria, voltado especialmente para o conceito de proporção no $8^{\circ} / 9^{\circ}$ ano de uma escola do campo. Logo, a pesquisadora traçou como metas: a) o reconhecimento da realidade dos alunos de uma escola do campo; b) a elaboração de uma sequência didática para explorar a fotografia com o intuito de trabalhar o conceito de proporção e promover o ensino de Geometria; c) analisar as conexões que podem ser estabelecidas pelos estudantes com base na fotografia a partir atividades.

Para alcançar os objetivos foram elaboradas atividades distribuídas num total de 6 encontros, em que os alunos foram orientados a registrar por meio de fotografias e filmagens a realidade da comunidade, buscando aspectos como a beleza e a harmonia do Campo, a destruição da natureza, a modernização no processo de produção e da vida do Campo, bem como suas moradias e o modo de viver. 
Posteriormente, o material levantado pelos alunos serviu de aporte para a exploração dos conceitos de perspectiva, formas geométricas (bidimensional e tridimensional), razão e proporção e, transformações isométricas.

Por fim, Frantz (2015) destaca que esta atividade serviu para a construção de um novo olhar sobre a fotografia, bem como, para a percepção da presença da Geometria na natureza, explorando conceitos matemáticos e ações oriundas do cotidiano de forma dinâmica.

Seguindo, analisamos a produção de Pereira (2013), na qual a autora busca compreender quais as possíveis contribuições que a aplicação de uma sequência de ensino, adaptada para uma escola do campo pode trazer para o Ensino de Estatística em uma turma do $6^{\circ}$ ano de Ensino Fundamental.

Para alcançar o citado objetivo foram percorridas algumas etapas: a primeira consistiu na aplicação de um questionário com o intuito de coletar algumas informações sobre o grupo de alunos, como conhecimentos e características. Após, a autora analisou o livro de Matemática disponível na escola, para realizar uma adaptação à realidade da mesma, elaborando propostas de ensino. Com base nas informações e construções das etapas anteriores, foi elaborada uma sequência de ensino envolvendo conceitos estatísticos.

Ressaltamos que os resultados obtidos foram marcados pela motivação dos alunos na participação, na coleta, organização e resumo das informações, de modo que, a partir destas competências, foi realizado um projeto no qual, por meio de dados estatísticos, foi possível socializar práticas em sala de aula, com base no debate de temas sociais oriundos da comunidade, promovendo o ensino de Estatística e a valorização cultural.

A produção de Lima (2017) buscou identificar se há contextualização de conceitos matemáticos vistos no curso PROCAMPO - Urca com os conhecimentos matemáticos de alunos oriundos de escolas do campo. Para isso, realizou um estudo de caso na Universidade Regional do Cariri - Urca, com a participação de 18 professores do curso Procampo, com o objetivo de averiguar como se dá o Ensino de Matemática.

Para alcançar o objetivo, a autora fez uso de observações, aplicação de questionário e entrevistas semiestruturadas, com professores que não participaram de formações para lecionar em escolas do campo.

Após a análise dos dados obtidos, chegou-se a conclusão de que para estes professores, se faz necessária a inclusão de momentos formativos que levem em consideração as vivências da comunidade, pois durante as intervenções pode-se observar a ausência de uma valorização de experiências que sejam oriundas do cotidiano e que podem estar implicadas ao desenvolvimento do ensino e aprendizagem da área da Matemática.

Ainda, Lima (2017) finaliza ressaltando que estas reflexões sobre o espaço e entorno da comunidade podem contribuir diretamente no ensino de Matemática, pois a partir disso, o sujeito pode se reconhecer como parte importante em seu espaço, em sua cultura e com isso valorizar os conhecimentos que a escola prega, resgatando assim, o desejo de conhecimento, e consequentemente na construção de um futuro com mais oportunidades. 


\subsection{Publicações referentes ao Ensino de Ciências Biológicas}

Durante a análise das produções, constatamos que 3 trabalhos se voltavam para a discussão de aspectos relacionados ao Ensino de Ciências, abordando em seu conteúdo questões sociais, socioambientais e temáticas adaptadas conforme suas localidades. O Quadro 2, sintetiza as produções desta categoria.

Quadro 2 - Publicações referentes ao Ensino de Ciências

\begin{tabular}{|c|c|c|c|c|}
\hline Autor & Título & Ano & Programa & Instituição \\
\hline $\begin{array}{l}\text { Elisabete } \\
\text { Franca }\end{array}$ & $\begin{array}{c}\text { Edocomunicação } \\
\text { Socioambiental: Uma } \\
\text { proposta Metodológica para } \\
\text { o trabalho da temática a } \\
\text { Ambiental no Contexto } \\
\text { escolar }\end{array}$ & 2016 & $\begin{array}{l}\text { Programa de Pós- } \\
\text { Graduação em } \\
\text { Ensino de Ciências } \\
\text { Naturais e } \\
\text { Matemática }\end{array}$ & $\begin{array}{l}\text { Universidade } \\
\text { Estadual do } \\
\text { Centro-Oeste }\end{array}$ \\
\hline $\begin{array}{l}\text { Edicleide da } \\
\text { Silva } \\
\text { Pereira }\end{array}$ & $\begin{array}{c}\text { Contribuições da Abordagem } \\
\text { temática Freiriana para o } \\
\text { Ensino de Ciências de uma } \\
\text { escola do campo de Iguaí/BA } \\
\text { Ilhéus - BA }\end{array}$ & 2015 & $\begin{array}{l}\text { Mestrado em } \\
\text { Educação em } \\
\text { Ciências }\end{array}$ & $\begin{array}{l}\text { Universidade } \\
\text { Estadual de } \\
\text { Santa Cruz }\end{array}$ \\
\hline $\begin{array}{l}\text { Luciane } \\
\text { Maffini } \\
\text { Schlottfeldt }\end{array}$ & $\begin{array}{c}\text { Oficinas Temáticas e o } \\
\text { Ensino de Ciências da } \\
\text { Natureza em uma Escola } \\
\text { do campo do Município de } \\
\text { Santa Maria, Rio Grande do } \\
\text { Sul }\end{array}$ & 2018 & $\begin{array}{l}\text { Programa de Pós- } \\
\text { Graduação em } \\
\text { Ensino de Ciências } \\
\text { e Matemática }\end{array}$ & $\begin{array}{l}\text { Universidade } \\
\text { Franciscana }\end{array}$ \\
\hline
\end{tabular}

Fonte: Dados da Pesquisa

A primeira produção analisada deste eixo foi a de Franca (2016), na qual a autora visou a elaboração de materiais paradidáticos na perspectiva socioambiental para que os mesmos fossem alternativas para os professores, envolvendo a educação ambiental crítica, e atendendo as necessidades da escola do campo, bem como suas especificidades.

Para realizar a proposta, participaram deste projeto professores do Colégio Estadual do Campo da Palmeirinha, localizado no município de Guarapuava-Paraná. Com um modelo de pesquisa participante, foi aplicado aos professores questionários e entrevistas a fim de avaliar se na visão e prática dos mesmos é possível articular os princípios da Educação do Campo com os objetivos da Educação Ambiental. As atividades foram realizadas em três etapas: a) levantamento prévio das questões pedagógicas das escolas; b) elaboração de um material como recurso metodológico para os professores; c) aplicação e validação do material por meio de oficinas com os professores.

Após todo o processo a autora destacou que não há articulações entre a prática dos professores com o Projeto Político Pedagógico da escola, e que os professores sentem dificuldades de se adequar a realidade da escola do campo devido à falta de recursos e materiais didáticos, sendo os materiais elaborados, essenciais para relacionar o tema com o contexto do campo; os reflexos desta atividade serão vistos na prática dos professores, que por sua vez quando dividirem suas experiências com os alunos, poderão atribuir significados aos conceitos trabalhados em sala de aula, quando se tratar da Educação Ambiental. 
A produção de Pereira (2015), buscou compreender quais são as contribuições da abordagem da temática freireana na elaboração de atividades para o Ensino de Ciências em uma escola do campo. Tomando como ponto de partida a questão "para onde vai o lixo do meio rural do município de Iguaí no estado da Bahia?" o estudo foi organizado em três fases: a) questionário com os professores para investigar suas concepções sobre a Educação do Campo; b) desenvolvimento das atividades de investigação com professores e alunos; c) entrevista semiestruturada com professores.

A autora ressalta que a Educação do Campo ainda é pouco explorada e discutida em trabalhos acadêmicos, mas que em sua pesquisa, foi possível observar que é necessário que haja processos de formação continuada para professores de escolas do campo, devido à necessidade da inserção de aspectos do campo no currículo escolar. Ainda, se faz necessário que o professor conheça sua realidade, para que possa explorá-la e passe a tornar o aluno o protagonista de seu aprendizado, discutindo em sala de aula questões oriundas de seu cotidiano.

Por fim, analisarmos a dissertação de Schlottfeldt (2018), em que a autora discute a inserção de Oficinas Temáticas (OT) para promoção do Ensino de Ciências da Natureza na escola do campo. Assim, a autora buscou identificar em documentos oficiais as orientações sobre a Educação do Campo na área de Ciências da Natureza no Ensino Fundamental. Ainda foi analisado o Projeto Político Pedagógico da escola a fim de que esse contribuísse na construção e organização das oficinas.

As oficinais foram baseadas em unidades temáticas, porém, a autora não deixa claro quais temas foram explorados, comentando, entretanto, que os mesmos estavam de acordo com os objetivos da Educação do Campo sobre as Ciências da Natureza.

Deste modo, Schlottfeldt (2018) ressalta que as OT são apropriadas e relevantes para escolas do campo, pois aliadas ao Ensino de Ciências da Natureza admitem potencialidades como, por exemplo, a oportunidade de problematizações sobre o ambiente no qual os alunos estão inseridos, bem como, a sustentabilidade e o empreendedorismo desenvolvidos por meio da produção de materiais e produtos tendo como fonte de recursos o próprio meio onde vivem.

Observando as três produções, foi possível verificar a preocupação quanto ao ensino via métodos diversificados, sejam eles oficinas temáticas, como apontado por Schlottfeldt (2018), ou questões de contexto regional, como aponta Pereira (2015) quando busca descobrir para onde vai o lixo da comunidade. Logo, observamos o intenso cuidado em enaltecer o ambiente, a comunidade e a pluralidade cultural existente nestas escolas, uma vez que as produções proporcionam alternativas para construção de um ensino baseado na realidade.

\subsection{Publicações referentes ao Ensino de Física}

Após as análises, observamos que somente 2 produções contemplavam em suas pesquisas o Ensino de Física empregado a questões culturais e étnicas na modalidade da Educação do Campo. O Quadro 3, apresenta as produções elencadas para esta categoria. 
Quadro 3 - Produções referentes ao Ensino de Física

\begin{tabular}{|c|c|c|c|c|}
\hline Autor & Título & Ano & Programa & Instituição \\
\hline $\begin{array}{c}\text { Nathan } \\
\text { Carvalho } \\
\text { Pinheiro }\end{array}$ & $\begin{array}{c}\text { Por uma pesquisa em Ensino de } \\
\text { Física menos Universal: Usando } \\
\text { um modelo teórico de níveis de } \\
\text { contexto Mutuamente } \\
\text { constitutivos para interpretar a } \\
\text { Educação Científica em diferentes } \\
\text { Idoculturas }\end{array}$ & 2016 & $\begin{array}{c}\text { Programa de } \\
\text { Pós-Graduação } \\
\text { em Ensino de } \\
\text { Física }\end{array}$ & $\begin{array}{c}\text { Universidade } \\
\text { Federal do Rio } \\
\text { Grande do Sul }\end{array}$ \\
\hline $\begin{array}{c}\text { Franciele } \\
\text { Franco Dias }\end{array}$ & $\begin{array}{c}\text { Articulação Freire-CTS: lançando } \\
\text { um olhar sobre as escolas do } \\
\text { campo }\end{array}$ & 2018 & $\begin{array}{c}\text { Pós-Graduação } \\
\text { em Educação } \\
\text { Matemática e } \\
\text { Ensino de Física }\end{array}$ & $\begin{array}{c}\text { Universidade } \\
\text { Federal de Santa } \\
\text { Maria }\end{array}$ \\
\hline
\end{tabular}

Fonte: Dados da Pesquisa

Para este tópico, destacamos somente duas produções nas quais discutiam aspectos sobre o Ensino de Física. A primeira trata-se da dissertação de Pinheiro (2016), em que o autor buscou investigar diferentes usos e sentidos da contextualização científica. Para isso, propôs um modelo para pensar no contexto, ou seja, tarefas nas quais nas quais possam ser expressos traços culturais presentes nos sujeitos.

A fim de avaliar os tipos de aprendizagens em diferentes níveis de contexto, foram realizados três estudos de caso, são eles: a) resolução de problemas com diferentes contextos aplicados com estudantes do Ensino Médio; b) concepções de interdisciplinaridade entre professores de ciências da natureza de escolas do campo, por meio de diálogos com docentes da Universidade; c) expectativas sobre a atividade docente, construção de planos de ensino sob o viés de licenciandos em Física e em Educação do Campo por meio de um questionário e trabalhos em grupo.

Após a análise das atividades, o autor ressalta que foi possível identificar a influência dos contextos nas atividades, alguns mais presentes que outros. Nos casos b e c, Pinheiro (2016) enaltece que se observou uma forte influência da Idocultura da Educação do Campo nas atividades.

Por fim, o autor alerta para a necessidade de se adequar as práticas escolares à Idocultura dos sujeitos, para elaborar um melhor planejamento e promover uma diversidade de contextos científicos oriundos do contexto no qual a comunidade está inserida.

A próxima produção se trata da dissertação de Dias (2018), que teve por objetivo, investigar elementos da teoria e da prática que podem nortear estratégias didático-metodológicas sob o viés dos pressupostos freireanos e da metodologia de ensino CTS, visando com isso contribuir para o ensino e aprendizagem de Física em escolas do campo.

Para alcançar tal objetivo, a autora realizou um levantamento em eventos da área de ensino, entrevista com professores e equipe diretiva de duas escolas do campo da região centro do estado do RS, análise do PPP destas escolas, além de uma entrevista com a assessoria das Escolas do Campo da Coordenadoria Regional de Educação.

Após o estudo, a autora selecionou três eixos para a análise, são eles: a) Educação do Campo ou Educação no Campo?; b) Estratégias Metodológicas para o Ensino de Física; c) Desafios e Possibilidades no trabalho docente. 
Logo, após discussão e análise sobre os eixos, a autora destaca que fica evidente a falta de formação inicial e continuada para o entendimento das questões do campo, que acabam por prejudicar o processo de ensino, seja ele de Física ou não, pois nem mesmo o currículo é pensado e construído a partir de questões de contexto de cada comunidade. Deste modo, se faz necessária a inclusão de práticas que valorizem o ensino e mostre um novo caminho para os professores, por meio da informação e da construção de materiais e recursos didáticos.

Assim como o Ensino de Ciências e Matemática, as produções de Física fazem referência ao contexto e como valorizá-lo por meio de atividades científicas. Assim, acreditamos ser este um dos pontos chaves para o avanço do ensino de modo geral em escolas do campo, a escola como centro de valorização da cultura e do conhecimento a partir dela.

\subsection{Publicações referentes ao Currículo}

Sobre o currículo, somente 4 produções discutiram aspectos sobre questões curriculares, propondo práticas diversificadas, entendendo as necessidades e diversidades das escolas do campo. Abaixo estão dispostas no quadro as produções desta categoria.

\begin{tabular}{|c|c|c|c|c|}
\hline Autor & Título & Ano & Programa & Instituição \\
\hline $\begin{array}{l}\text { Lubna Chagas } \\
\text { Peixer }\end{array}$ & $\begin{array}{l}\text { Necessidades Formativas e a } \\
\text { prática Como Componente } \\
\text { Curricular em Documentos } \\
\text { Curriculares do curso de } \\
\text { licenciatura em Química do } \\
\text { Instituto Federal de Santa } \\
\text { Catarina-SJ }\end{array}$ & 2018 & $\begin{array}{l}\text { Programa de } \\
\text { Pós-Graduação } \\
\text { em Educação } \\
\text { Científica e } \\
\text { Tecnológica }\end{array}$ & $\begin{array}{c}\text { Universidade } \\
\text { Federal de Santa } \\
\text { Catarina }\end{array}$ \\
\hline $\begin{array}{l}\text { Linlya Natassia } \\
\text { Sachs } \\
\text { Camerlengo de } \\
\text { Barbosa }\end{array}$ & $\begin{array}{c}\text { Entendimento a } \\
\text { Respeito da Matemática na } \\
\text { Educação do Campo: } \\
\text { Questões sobre currículo }\end{array}$ & 2014 & $\begin{array}{l}\text { Programa de } \\
\text { Pós-Graduação } \\
\text { em Educação } \\
\text { Matemática }\end{array}$ & $\begin{array}{l}\text { Universidade } \\
\text { Estadual Paulista }\end{array}$ \\
\hline $\begin{array}{l}\text { Ronilce Maria } \\
\text { Garcia Lopes }\end{array}$ & $\begin{array}{c}\text { Histórias de uma } \\
\text { Pesquisa(dora) em uma } \\
\text { escola do campo com } \\
\text { professores que lecionam } \\
\text { matemática }\end{array}$ & 2016 & $\begin{array}{l}\text { Programa de } \\
\text { Pós-Graduação } \\
\text { em Educação } \\
\text { Matemática }\end{array}$ & $\begin{array}{l}\text { Universidade } \\
\text { Estadual Paulista }\end{array}$ \\
\hline $\begin{array}{l}\text { Tatiani Maria } \\
\text { Schneider }\end{array}$ & $\begin{array}{l}\text { Abordagem Temática e o } \\
\text { Ensino de Física: Articulações } \\
\text { com a Educação do Campo }\end{array}$ & 2017 & $\begin{array}{l}\text { Programa de } \\
\text { Pós-Graduação } \\
\text { Em Educação } \\
\text { Matemática e } \\
\text { Ensino de Física }\end{array}$ & $\begin{array}{c}\text { Universidade } \\
\text { Federal de Santa } \\
\text { Maria }\end{array}$ \\
\hline
\end{tabular}

Fonte: Dados da Pesquisa

A primeira produção deste eixo é a de Peixer (2018), que faz referência ao curso de Licenciatura em Ciências da Natureza, porém com foco específico na área da Química, e busca responder a seguinte questão: como a prática comum curricular está organizada no curso de Química do IF de Santa Catarina? Para responder a este problema, a autora fez uma análise de documentos curriculares institucionais do curso, com o intuito de investigar as práticas comuns curriculares no curso e seus reflexos na formação docente.

Para isso, foram analisados o Projeto Pedagógico de Curso (PPC), os planos de ensino e os diários de classe. Após esta etapa, Peixer (2018) constatou que as Parâmetros Curriculares Nacionais (PCN's) 
podem contribuir para a formação docente caso haja ideias para fugir do chamado "senso comum pedagógico", que é estabelecido na área da Educação, podendo fazer com que o futuro professor reflita sobre sua prática.

A próxima produção, reflete sobre questões curriculares sobre a Matemática na Educação do Campo. Barbosa (2014) objetivou discutir formas de entender o currículo de Matemática e como ele está estruturado na Educação do Campo. Para isso, a autora traçou imagens panorâmicas com base em um levantamento feito em publicações acadêmicas dos cursos de Licenciatura em Educação do Campo, estes voltados para a habilitação em Matemática, e ainda foram realizadas sete entrevistas.

Após a análise dos materiais coletados, a autora aponta quatro aspectos relevantes: a) os conteúdos matemáticos trabalhados em escolas do campo devem ser os mesmos de qualquer outra escola, mas, devem partir da realidade da comunidade; b) a inclusão de saberes locais nos programas curriculares; c) não deve haver especificidade no programa de Matemática nas escolas do campo; d) a escola devia oferecer uma formação continuada para os professores rurais.

Seguindo, Lopes (2016) traz as histórias de uma pesquisadora que leciona Matemática em uma escola do campo, enaltecendo como os professores têm refletido e compreendido esse espaço. Assim, a autora se cerca de conceitos oriundos da Educação do Campo, da Educação Matemática e principalmente o diaa-dia de uma escola de zona rural, norteadas pelo referencial curricular do Mato Grosso do Sul.

Assim, a história contada em volta deste contexto, foi inspirada na cartografia, na qual foram discutidos e apontados alguns aspectos provenientes do chão da escola, sem muitos detalhes do que foi realizado.

A próxima produção é a de Schneider (2017), em que a autora indaga sobre a ampliação dos estudos sob o viés da abordagem temática e a articulação da mesma com o Ensino de Física, e assim questionando como a mesma auxiliar para a construção de um processo formativo em escolas do campo.

Para alcançar este objetivo, a autora realizou buscas em anais de eventos e revistas da área de Ensino de Física, além de entrevistas e questionários aplicados com professores de uma escola do campo. A análise feita dos eventos e periódicos foi classificada em cinco categorias, são elas: a) Articulação entre a perspectiva da Abordagem Temática e a Educação do Campo; b) A construção do currículo a partir da Abordagem Temática; c) Abordagem de temas a partir do currículo pré-estabelecido; d) A Abordagem Temática e o trabalho em sala de aula a partir dos Três Momentos Pedagógicos; e) Trabalho interdisciplinar na Abordagem Temática.

Já as entrevistas foram analisadas com o intuito de levantar as principais características da prática docente nas escolas. Por fim, Schneider (2017), destaca que nem todas as produções analisadas discutem a Abordagem Temática na perspectiva da Educação do Campo e que quando são discutidas, não mudam significativamente o currículo.

A autora ainda faz uma ressalva alertando que as escolas ainda parecem dar importância e privilegiar aspectos que não fazem parte de seu contexto ou de sua comunidade, fato este que contribui para um distanciamento do cotidiano com o científico.

Ao analisarmos os trabalhos dessa categoria percebemos que, em sua grande maioria, os autores discutem formas de melhorar e contribuir para a construção de um currículo mais adaptado as 
especificidades do campo, de modo que passem a fornecer estrutura para o desenvolvimento das atividades nas escolas, auxiliando tanto o professor quanto o aluno.

\subsection{Publicações referentes ao tema Formação de Professores}

Continuando nossa análise, nos deparamos com uma quantidade expressiva de produções que discutiam aspectos relacionados à formação de professores em escolas do campo na área da Matemática, Ciências Biológicas e a própria Licenciatura em Educação do Campo, contabilizando assim 7 produções que estão dispostas no quadro abaixo.

Quadro 5 - Produções relativas a Formação de Professores

\begin{tabular}{|c|c|c|c|c|}
\hline Autor & Título & Ano & Programa & Instituição \\
\hline $\begin{array}{l}\text { Cristiano Lima } \\
\text { dos Santos } \\
\text { Almeida }\end{array}$ & $\begin{array}{l}\text { Situação de estudo na } \\
\text { formação de professores em } \\
\text { escolas do campo de } \\
\text { Coaraci/BA }\end{array}$ & 2017 & $\begin{array}{l}\text { Mestrado em } \\
\text { Educação em } \\
\text { Ciências }\end{array}$ & $\begin{array}{l}\text { Universidade } \\
\text { Estadual de } \\
\text { Santa Cruz }\end{array}$ \\
\hline $\begin{array}{l}\text { Aldinete Silvino } \\
\text { De Lima }\end{array}$ & $\begin{array}{l}\text { A relação entre conteúdos } \\
\text { matemáticos } \\
\text { e o campesinato na Formação } \\
\text { de professores de Matemática } \\
\text { em cursos de Licenciatura em } \\
\text { Educação do Campo }\end{array}$ & 2018 & $\begin{array}{l}\text { Programa de Pós- } \\
\text { Graduação em } \\
\text { Educação } \\
\text { Matemática e } \\
\text { Tecnológica }\end{array}$ & $\begin{array}{l}\text { Universidade } \\
\text { Federal de } \\
\text { Pernambuco }\end{array}$ \\
\hline $\begin{array}{l}\text { Leila Lesandra } \\
\text { Paiter }\end{array}$ & $\begin{array}{c}\text { Reflexões sobre a } \\
\text { Formação Docente na área de } \\
\text { conhecimento Ciências da } \\
\text { Natureza: a licenciatura em } \\
\text { Educação do Campo -UFSC }\end{array}$ & 2017 & $\begin{array}{l}\text { Programa de Pós- } \\
\text { Graduação em } \\
\text { Educação Científica } \\
\text { e Tecnológica }\end{array}$ & $\begin{array}{c}\text { Universidade } \\
\text { Federal de Santa } \\
\text { Catarina }\end{array}$ \\
\hline $\begin{array}{c}\text { Lucia Maria } \\
\text { Batista Fonseca }\end{array}$ & $\begin{array}{l}\text { Um olhar sobre a Formação de } \\
\text { professores que ensinam } \\
\text { Matemática nos Anos Iniciais do } \\
\text { Ensino Fundamental em } \\
\text { Escolas do Campo }\end{array}$ & 2017 & $\begin{array}{l}\text { Programa de Pós- } \\
\text { Graduação em } \\
\text { Docência em } \\
\text { Educação em } \\
\text { Ciências e } \\
\text { Matemática }\end{array}$ & $\begin{array}{l}\text { Universidade } \\
\text { Federal do Pará }\end{array}$ \\
\hline $\begin{array}{l}\text { Sueli Fagundes } \\
\text { Moreira }\end{array}$ & $\begin{array}{l}\text { Construção de Competências e } \\
\text { Formação Continuada de } \\
\text { Professores do Ensino } \\
\text { Fundamental em Ilheus, Bahia, } \\
\text { a partir do Ensino de Ciências }\end{array}$ & 2018 & $\begin{array}{l}\text { Programa de Pós- } \\
\text { Graduação de } \\
\text { Educação em } \\
\text { Ciências }\end{array}$ & $\begin{array}{l}\text { Universidade } \\
\text { Estadual de } \\
\text { Santa Cruz }\end{array}$ \\
\hline $\begin{array}{l}\text { Denise Godoi } \\
\text { Ribeiro Sanches }\end{array}$ & $\begin{array}{l}\text { Educação na Escola do } \\
\text { campo: processos, } \\
\text { procedimentos, e práxis } \\
\text { pedagógicas no contexto } \\
\text { escolar }\end{array}$ & 2016 & $\begin{array}{l}\text { Programa de Pós- } \\
\text { Graduação em } \\
\text { Educação para } \\
\text { Ciências e } \\
\text { Matemática }\end{array}$ & $\begin{array}{l}\text { Universidade } \\
\text { Estadual de } \\
\text { Maringá }\end{array}$ \\
\hline $\begin{array}{c}\text { Maluza } \\
\text { Gonçalves Dos } \\
\text { Santos }\end{array}$ & $\begin{array}{l}\text { Educação Matemática nos } \\
\text { cursos de Licenciatura em } \\
\text { Educação do Campo no Rio } \\
\text { Grande do Sul: diálogos com } \\
\text { Professores formadores }\end{array}$ & 2017 & $\begin{array}{l}\text { Programa de Pós- } \\
\text { Graduação em } \\
\text { Educação } \\
\text { Matemática e Ensino } \\
\text { de Física } \\
\end{array}$ & $\begin{array}{l}\text { Universidade } \\
\text { Federal de } \\
\text { Santa Maria }\end{array}$ \\
\hline
\end{tabular}

Fonte: Dados da Pesquisa 
O eixo sobre formação de professor foi o que contabilizou maior número de trabalhos em nossa pesquisa, todos com a mesma preocupação, formar profissionais capacitados para enfrentar as especificidades das comunidades rurais, de modo a construir um modelo educacional mais específico.

A primeira produção, de Almeida (2017), discute quais são as contribuições que a vivência de atividades da proposta de uma situação de estudo pode trazer para a formação continuada de professores de uma escola do campo do município de Coaraci na Bahia.

A fim de discutir aspectos como as classes multisseriadas, o autor realizou sua pesquisa tendo como subsídios a aplicação de um questionário, análise do PPP da escola, um curso de formação continuada com os professores e entrevistas semiestruturadas, com o objetivo de observar as demandas, contribuições e reflexos sobre a prática dos professores.

Assim, utilizando como metodologia de análise a Análise Textual Discursiva (ATD), o autor averiguou que momentos como cursos de formação servem para os docentes refletirem sobre sua prática e repensarem em uma reorganização curricular. Além disso, como se tratam de turmas multisseriadas, se constatou que é necessária uma delimitação de temas que partam das vivências dos alunos e que façam sentido para todo o grupo, pois a construção da atividade deve se dar de forma coletiva e interdisciplinar.

Já a tese de Lima (2018) discute o saber matemático e o campesino na formação de professores de Matemática na Licenciatura em Educação do Campo, com o objetivo de compreender a relação dos conteúdos matemáticos com aspectos políticos, sociais e culturais do campo na formação dos professores.

Os dados desta pesquisa foram coletados a partir do PPC dos cursos de três instituições localizadas nas regiões Nordeste, Centro-Oeste e Sudeste. Ainda, foram entrevistados oito professores formadores, bem como, o acompanhamento de três disciplinas ministradas nestes cursos.

Após a análise do PPC, o autor destaca que se percebe uma preocupação com as dimensões políticas, culturais e sociais das comunidades, principalmente sobre questões de organização curricular. Ainda, durante as entrevistas os professores ressaltaram que o diálogo, a investigação, e a crítica são importantes para esta organização.

Porém, a prática em sala de aula ainda é outra, pois todas as questões levantadas nas entrevistas e no PPC ainda estão longe de ser implementadas em sala de aula, o que pode ser visto nas observações das aulas, precisando ser repensada e alinhada aos documentos norteadores do curso.

Deste modo, Lima (2018) afirma que sob a perspectiva do diálogo, da investigação e da crítica é possível, por meio de ambientes de aprendizagem, realizar uma mudança, tanto social quanto humana.

A dissertação de Paiter (2017) discute o papel das Ciências da Natureza na Licenciatura em Educação do Campo, com o intuito de identificar e refletir quais as percepções dos docentes sobre a mesma. Para realizar a pesquisa, foram feitas buscas em documentos que norteiam o currículo do curso, além de uma conversa com os professores sobre suas percepções com relação a formação docente para as Ciências da Natureza.

Após todo o processo de análise dos dados, a autora constatou que toda a formação recebida pelos alunos do curso possui pontos de proximidade e de distanciamento dos pressupostos da formação de 
área do conhecimento Ciências da Natureza, ainda por se tratar de um curso voltado para profissionais em uma realidade de escolas do campo.

Fonseca (2017) parte para outro viés, diferentemente das produções descritas anteriormente, pois a autora analisa a formação do professor de Matemática dos Anos Iniciais de escolas do campo, respondendo como uma proposta de formação continuada pode orientar o trabalho didático-pedagógico do professor quando o mesmo ensina Matemática nos Anos Iniciais em uma escola de zona rural.

Os sujeitos da autora foram cinco professores de uma escola do campo situada no estado do Pará, em que os docentes participaram de oito encontros formativos, este sendo um modelo de formação continuada. Desta forma, o material coletado nos encontros foi dividido em duas partes: a) Compressões dos professores sobre a formação continuada e sua prática; b) Saberes docentes na prática pedagógica.

No desenvolver do trabalho, os professores alegaram que as principais dificuldades vistas por eles no ensino de Matemática para os Anos Iniciais estão cercadas por a falta de discussão na formação inicial por eles vividos, pela forma como a formação continuada tem contribuído pouco na melhora das práticas, e que a equipe de gestão não se envolve nas ações de sala de aula.

Logo, as atividades propostas por Fonseca (2017) acabaram por estimular os professores, de modo que, os mesmos ressaltaram a importância de atividades formativas sobre o contexto da comunidade, nas quais são orientados ao como ensinar, e como aprender, e os alunos aprendem a aprender Matemática.

Ainda nessa categoria, Moreira (2018), discute a formação continuada de professores e suas competências. A pesquisa da autora objetivou analisar a construção de conhecimentos sobre o Ensino de Ciências, bem como, o desenvolvimento de competências oriundos de vivências e reflexões, teorias e práticas, e ainda atividades investigativas com um grupo de professores dos Anos Iniciais que atuam em escolas do campo da região Sul da Bahia.

Para alcançar o objetivo citado, a autora organizou três encontros formativos, sob o viés do Ensino por meio da investigação, verificando que este modelo de formação possibilita uma maior organização e dinâmica para se trabalhar com professores quando os mesmos são os aprendizes. Assim, a pesquisa de Moreira (2018) ressalta o tripé necessário nestes momentos formativos: os aportes teóricos, didáticos e práticos.

Por fim, a pesquisadora aponta que com base neste tripé, os professores podem construir conhecimentos relacionas a Educação Científica, vislumbrando uma alfabetização científica com os alunos, enaltecendo que esta é um suporte não somente para o Ensino de Ciências, mas também para as demais áreas do conhecimento. Deste modo, a autora finaliza dizendo que sua dissertação defende que estes três aspectos da formação não acabem restritos somente ao Ensino de Ciências, mas que seja vivenciada em outras áreas.

A próxima produção deste eixo é a de Sanches (2016), na qual a autora tem como temática a Educação Ambiental (EA) em uma escola do campo do estado do Paraná, objetivando reconhecer a práxis da EA na escola do campo, em conformidade com os processos, práticas e procedimentos pedagógicos.

Para alcançar tal objetivo, a autora organizou um grupo de estudos e ainda entrevistas semiestruturadas com o grupo de professores. Assim pode concluir que a EA não está contemplada nas diretrizes curriculares do estado, e no PPP da escola não há discussão sobre o tema. Com relação aos planos de 
trabalho dos professores, a EA aparece de forma camuflada, superficial e sem enfoque preciso, contudo, ressaltando que os professores tem conhecimento da importância da EA, mas não dispõem de formações sobre o assunto, assim, quando promovem atividade desta natureza, estas são norteadas por suas específicas áreas de atuação.

Deste modo, Sanches (2016), destaca que o grupo de estudos fortaleceu discussões sobre o tema, oportunizando momentos de reflexão sobre a prática pedagógica.

O último dos trabalhos dessa categoria é a dissertação de Santos (2017), na qual a autora investiga a estrutura dos cursos presenciais de Licenciatura em Educação do Campo no estado do Rio Grande do Sul, com o objetivo de descobrir como se dá o processo formativo para a área das Ciências da Natureza.

Para isso, a autora fez uso de instrumentos como: a) entrevista semiestruturada com os professores formadores; b) diálogo com os alunos de uma das instituições; c) tópicos de acompanhamento das universidades.

Após análise dos dados coletados, a autora constatou que há uma relação dialógica entre o discurso dos professores do componente curricular de Matemática e os demais professores que estão consolidando um curso de licenciatura com muitas peculiaridades, preconizando a interdisciplinaridade.

Assim, observamos que em todas as produções, foram visíveis as preocupações dos pesquisadores com a inserção de temas geradores e de propostas para inclusão de práticas no currículo das escolas do campo, e ainda, que os professores se sentem desamparados para realizar mudanças curriculares, pois não recebem a devida formação continuada para isso. Assim, ressaltamos a importância de pesquisas que discutam esses aspectos, de modo a colaborar com os professores, seja por meio de intervenções, oficinas, grupos de estudos e momentos de reflexão sobre a prática e como adaptá-la a cada realidade.

\subsection{Publicações referentes à Pedagogia da Alternância}

A chamada Pedagogia da Alternância é um método de ensino muito utilizado em escolas campo, pois se trata de uma metodologia que tem por objetivo a interação do estudante com o meio onde vive, ou seja, o campo, oferecendo momentos de atividades escolares e práticas oriundas do campo, relacionando experiências entre termos técnicos e práticos.

A formação dos alunos neste modelo de ensino possibilita a educação de tempo integral, o envolvimento das famílias e o diálogo entre as duas faces do processo da formação dos educandos (JESUS, 2010).

Com isso, apresentamos o único trabalho dessa categoria, que discute a Pedagogia da Alternância como alternativa para a promoção do ensino em escolas da zona rural.

\begin{tabular}{|c|c|c|c|c|}
\hline Autor & Título & Ano & Programa & Instituição \\
\hline $\begin{array}{c}\text { Cidimar } \\
\text { Andreatta }\end{array}$ & $\begin{array}{l}\text { Etnomatemática e Educação do } \\
\text { Campo: o caso da escola } \\
\text { municipal comunitária Rural "Padre } \\
\text { Fulgênio do Menino Jesus" do } \\
\text { Município de Colatina, estado do } \\
\text { Espírito Santo. }\end{array}$ & 2013 & $\begin{array}{l}\text { Mestrado } \\
\text { Profissional em } \\
\text { Educação em } \\
\text { Ciências e } \\
\text { Matemática }\end{array}$ & $\begin{array}{l}\text { IF Espírito } \\
\text { Santo }\end{array}$ \\
\hline
\end{tabular}


A dissertação de Andreatta (2013) buscou investigar como a Pedagogia da Alternância contribuiu no processo educativo de uma escola do campo do interior do Espírito Santo após ser implementada como metodologia de trabalho.

Analisando a realidade do educandário, o autor percebeu que a Matemática passou a ter sentido e validade para o grupo pois os conceitos passaram a ser discutidos por meio de atividades presentes na vida no campo; quase uma aproximação com a Etnomatemática.

Durante sua análise, Andreatta (2013), utilizou vários instrumentos de coleta de dados durante suas intervenções no ambiente escolar: a) situações-problemas; b) observações de aulas; c) entrevistas e questionários semiestruturados; d) diário de campo.

Após análise dos dados obtidos, o autor constatou que a compreensão de conteúdos matemáticos é muito mais facilitada e contextualizada pela integração de conhecimentos cotidianos e escolares. Ainda, o autor apresenta uma cartilha contendo sugestões de atividades que podem basear trabalhos pedagógicos nos anos finais do Ensino Fundamental, valorizando fatores oriundos da cultura do campo.

Desta forma, a Pedagogia da Alternância apesar de ser uma metodologia nova no cenário atual é uma alternativa que pode ser voltada especificamente para o trabalho dos professores em escolas do campo, pois se adapta muito bem a realidade, as peculiaridades e a flexibilidade que a prática nestas comunidades deve ter.

\section{DISCUSSÕES}

Após discutir e apresentar todos os trabalhos selecionados em nossa busca, destacamos como sendo um ponto negativo o fato de que todas as produções tratam somente de áreas específicas como a Matemática, a Física e as Ciências Biológicas e não especificamente do Ensino de Ciências e Matemática de forma conjunta, ou seja, ainda há uma compartimentalização de saberes. Somente Moreira (2018) destaca a importância das áreas trabalharem de forma conjunta para alfabetizar os alunos cientificamente.

Outro fato que merece ressalva é que as propostas, tanto as voltadas para o ensino e aprendizagem dos alunos como as que envolvem formação de professores e currículo, tem como intuito principal a inserção de questões cotidianas no ambiente escolar e acadêmico, pois este é um fato que faz diferença na qualidade da aprendizagem.

No eixo da formação de professores, os participantes de algumas pesquisas ressaltaram que a falta de suporte como formações continuadas, estrutura curricular, grupos de estudo, prejudica diretamente suas práticas, acarretando na construção de métodos de ensino vazios para o aluno.

Logo, as formações continuadas, principalmente em escolas do campo, podem e devem ser vistas como alternativas, ou estímulo para os mesmos. Como aponta Fonseca (2017), os professores quando participam de formação, grupos e aulas, destacam estas atividades como momentos de discussão sobre aspectos de escolas do campo, das peculiaridades e principalmente de métodos para diversificar 0 ensino, o que acaba por facilitar o desenvolvimento da construção da aprendizagem.

Já as publicações que se voltavam para o Ensino tanto de Ciências Biológicas, Matemática, e Física, acabaram por discutir aspectos de como melhorar e introduzir elementos, ações ou práticas no cotidiano 
escolar, sendo estas baseadas em elementos que fazem parte da vida dos alunos e que estejam presentes em condutas da comunidade escolar.

Ainda, contamos com dissertações como a de Lima (2017) em que a autora analisa se há uma relação entre os conceitos vistos em um curso PRONACAMPO, com os conceitos oriundos de escolas do campo.

Além do mais, ainda tivemos como resultado, publicações que seguem a linha de Pereira (2013), ou seja, que trabalham na compreensão das contribuições que sequências didáticas podem trazer para o ensino no Ensino Fundamental.

Deste modo, concluímos que de maneira geral todas as propostas se preocupam com os aspectos importantes e fundamentais das comunidades nas quais as escolas se encontram, se preocupando com uma aprendizagem mais carregada de significados, tanto da Educação Básica quanto no Ensino Superior.

\section{CONCLUSÃO}

Esse trabalho teve por objetivo, mapear e analisar as produções acadêmicas de programas de pósgraduação em Ensino de Ciências e Matemática voltadas à modalidade da Educação do Campo, com o intuito de explorar as principais alternativas que estão sendo desenvolvidas para suprir as necessidades destas comunidades.

Após a análise realizada, constatamos que o Ensino de Ciências e Matemática sob a perspectiva da Educação do Campo ainda é um tema pouco explorado no âmbito acadêmico, no nível das pesquisas de pós-graduação Stricto Sensu.

Outro ponto de ressalva é a compartimentalização de saberes, ou seja, ainda existente uma fragmentação de saberes nas escolas do campo, oriunda de uma má organização curricular, e esta afeta o rendimento das atividades, criando um ciclo vicioso e fragmentado, onde nos preocupamos somente com o produto final e esquecemo-nos do processo de aprendizagem em si (SEVERINO, 2003).

Assim, ressaltamos como sendo importante a inclusão e a promoção de práticas oriundas do meio acadêmico nestas escolas, com o intuito de auxiliar os professores em como refletir e construir atividades que estejam ligadas com os conhecimentos, estes advindos da cultura do campo, enaltecendo assim as peculiaridades do espaço, e desconstruindo o modelo urbanoide imposto nos dias de hoje e ainda, estreitando ainda mais o distanciamento entre a academia e a escola.

Sendo assim, finalizamos esta pesquisa destacando que o campo possui muitas possibilidades, sejam elas valores, crenças, concepções e modos de vida, o que exige do professor uma adaptação, uma flexibilidade e um novo olhar sobre as possibilidades de modificar sua prática.

\section{REFERÊNCIAS}

ALMEIDA, C. L. dos. S. Situação de estudo na Formação de Professores em scolas do campo de Coaraci/BA. 2017. 119 f. Dissertação (Mestrado em Educação em Ciências). Universidade Estadual de Santa Cruz, Ilhéus, 2017.

ANDREATTA, C. Etnomatemática e Educação do Campo: O caso da Escola Municipal Comunitária Rural Padre Fulgêncio do Menino Jesus, município de Colatina, estado do Espírito Santo. 2013. 153 f. 
Dissertação (Mestrado Profissional em Educação em Ciências e Matemática). Instituto Federal de Educação, Ciência e Tecnologia do Espírito Santo, Vitória, 2013.

Associação Brasileira de Pesquisa em Educação e Ciências (ABRAPEC). Comitê Assessor de Educação (CNPq). Coordenação de área 46 - Ensino de Ciências e Matemática (CAPES). Sociedade Brasileira para o Progresso da Ciência (SBPC). Sociedade Brasileira de Física (SBF). Sociedade Brasileira de Educação Matemática (SBEM). Sociedade Brasileira de Ensino de Biologia (SBEnBio). Subsídios da área de Ensino de Ciências e Matemática para a $4^{a}$ CNCTI e Conferência Regional Sudeste. Parc. Estrat. ed. especial. v. 16. no 36. p. 51-58. Brasilia, DF.

BARBOSA, L. N. S. C. de. Entendimentos a respeito da matemática na educação do campo: questões sobre currículo. 2014. 234 f. Tese (Doutorado em Educação Matemática). Universidade Estadual Paulista Júlio de Mesquita Filho, Rio Claro, 2014.

DIAS, F. F. Ensino de Física a partir da articulação freire-cts: Lançando um olhar sobre as escolas do campo. 2018. 113 f. Dissertação (Mestrado em Educação Matemática e Ensino de Física). Universidade Federal de Santa Maria, Santa Maria, 2018.

FRANCA, E. Educomunicação Ambiental: Uma proposta metodológica para o trabalho da temática ambiental no contexto escolar. 2016. 135 f. Dissertação (Mestrado Profissional em Ensino de Ciências Naturais e Matemática). Universidade Estadual do Centro-Oeste, Guarapuava, 2016.

FRANTZ, D. de. S. F. da. S. Potencialidades da Fotografia para o Ensino de Geometria e Proporção em uma Escola do Campo. 2015. 206 f. Dissertação (Mestrado Profissional em Ensino de Matemática). Universidade Federal do Rio Grande do Sul, Porto Alegre, 2015.

FONSECA, L. M. B. Um Olhar sobre a Formação de Professores que ensinam Matemática nos Anos Iniciais do Ensino Fundamental em Escolas do Campo. 2017. 159 f. Dissertação (Mestrado Profissional em Docência em Educação em Ciências e Matemáticas). Universidade Federal do Pará, Belém, 2017.

LEITE, S. C. Escola rural: urbanização e políticas educacionais. 2. ed. São Paulo: Cortez, 2002.

LIMA, S. de. O. Ensino de Matemática na Educação do Campo: Um estudo de caso no curso PRONACAMPO - URCA. 2017. 105 f. Dissertação (Mestrado em Ensino de Ciências e Educação Matemática). Universidade Estadual da Paraíba, Campina Grande, 2017.

LIMA, A. S. de. A relação entre conteúdos matemáticos e o campesinato na Formação de Professores de Matemática em cursos de Licenciatura em Educação do Campo. 2018. 215 f. Tese (Doutorado em Educação Matemática e Tecnológica). Universidade Federal de Pernambuco, Recife, 2018.

LOPES, R. M. G. Histórias de uma pesquisa(dora) em uma escola do campo com professores que lecionam Matemática. 2016. 143 f. Dissertação (Mestrado em Educação Matemática). Universidade Estadual Paulista Júlio de Mesquita Filho, Rio Claro, 2016.

LORENZATO, S. Para aprender matemática. 3. ed. Campinas: Autores Associados, 2010.

MOREIRA, S. F. Construção de Competências e Formação Continuada de Professores do Ensino Fundamental em Ilhéus, Bahia a Partir do Ensino de Ciências por Investigação. 2018. 133 f. Dissertação (Mestrado em Educação em Ciências). Universidade Estadual de Santa Cruz, Ilhéus, 2018. 
PACHECO, M. B. ANDREIS, G. da. S. L. Causa das dificuldades de aprendizagem em Matemática: percepção de professores e estudantes do $3^{\circ}$ ano do Ensino Médio. In: Revista Principia. n. 38, p. 105-119, 2017.

PAITER, L. L. Reflexões sobre a Formação Docente na área de conhecimento Ciências da Natureza: A Licenciatura em Educação do Campo - UFSC. 2017190 f. Dissertação (Mestrado em Educação Científica e Tecnológica). Universidade Federal de Santa Catarina, Florianópolis, 2017.

PEIXER, L. C. Necessidades Formativas e a Prática como componente curricular em documentos curriculares do curso de Licenciatura em Química do Instituto Federal da Santa Catarina - SJ. 2018. 131 f. Dissertação (Mestrado em Educação Científica e Tecnológica). Universidade Federal de Santa Catarina, Florianópolis, 2018.

PEREIRA, L. B. C. Ensino de Estatística na Escola do Campo: Uma proposta para um $6^{\circ}$ ano do Ensino Fundamental. 2013. 139 f. Dissertação (Mestrado Profissional em Ensino de Ciências e Tecnologia). Universidade Tecnológica Federal do Paraná, Ponta Grossa, 2013.

PEREIRA, E. da. S. Contribuições da Abordagem temática Freireana para o Ensino de Ciências de uma escola do campo de Iguaí/BA Ilhéus - BA. 2015. 144 f. Dissertação (Mestrado em Educação em Ciências). Universidade Estadual de Santa Cruz, Ilhéus, 2015.

PINHEIRO, N. C. Por uma pesquisa em ensino de física menos universal: usando um modelo teórico de níveis de contexto mutuamente constitutivos para interpretar a educação científica em diferentes idioculturas. 2016. 162 f. Tese (Doutorado em Ensino de Física). Universidade Federal do Rio Grande do Sul, Porto Alegre, 2016.

SANCHES, D. G. R. Educação Ambiental na escola do campo: processos, procedimentos e práxis pedagógicas no contexto escolar. 2016. 337 f. Tese (Doutorado em Educação para a Ciência e a Matemática). Universidade Estadual de Maringá, Maringá, 2016.

SANTOS, M. G. dos. Educação Matemática nos cursos de Licenciatura em Educação do Campo no Rio Grande do Sul: Diálogos com professores formadores. 2017. 117 f. Dissertação (Mestrado em Educação Matemática e Ensino de Física). Universidade Federal de Santa Maria, Santa Maria, 2017.

SANTOS, S. R. M. Ensinar Matemática na Educação Infantil do Campo: análises em escolas do município de Igarassu. 2018. 169 f. Dissertação (Mestrado em Educação Matemática e Tecnológica) Universidade Federal de Pernambuco, Recife, 2018.

SCHLOTTFELDT, L. M. Oficinas Temáticas e o Ensino de Ciências da Natureza em uma escola do campo do município de Santa Maria, Rio Grande do Sul. 201890 f. Dissertação (Mestrado Profissional em Ensino de Ciências e Matemática). Universidade Franciscana, Santa Maria, 2018.

SCHNEIDER, T. M. A abordagem temática e o Ensino de Física: Articulação com a Educação do Campo. 2017. 132 f. Dissertação (Mestrado em Educação Matemática e Ensino de Física). Universidade Federal de Santa Maria, Santa Maria, 2017.

SILVA, K. A. de L. Concepções e práticas da educação do campo: um estudo com professores em formação. 2017. 325 f. Tese (Doutorado em Educação) - Centro de Educação, Universidade Federal do Rio Grande do Norte, Natal, 2017. 